\title{
HUBUNGAN SANITASI LINGKUNGAN RUMAH TERHADAP KEJADIAN INFEKSI KECACINGAN PADA ANAK SEKOLAH DASAR
}

\section{Umi Mahmudah}

Program Studi S1-Ilmu Gizi Universitas Respati Yogyakarta Jl. Laksda Adisucipto, Caturtunggal, Kec. Depok, Kabupaten Sleman, Daerah Istimewa Yogyakarta 55281. Email: mahmudah_umi@ymail.com

\begin{abstract}
ABSTRAK
Gizi merupakan salah satu faktor penentu kualitas sumber daya manusia. Masalah gizi tidak hanya dipengaruhi oleh kurangnya asupan makanan, akan tetapi juga dipengaruhi oleh infeksi, salah satunya adalah infeksi kecacingan. Siklus hidup cacing dipengaruhi oleh beberapa faktor yaitu kondisi sanitasi lingkungan, perilaku personal hygiene, serta kondisi sosio ekonomi demografi daerah sekitar. Tujuan dari penelitian ini adalah untuk mengetahui hubungan sanitasi lingkungan rumah terhadap kejadian infeksi kecacingan pada anak sekolah dasar. Penelitian ini menggunakan teknik observasional dengan rancangan cross sectional, pada populasi anak sekolah dasar kelas 1 sampai kelas 5 di SD Barengan Kecamatan Teras Kabupaten Boyolali. Data kecacingan pada anak diperoleh dengan pengambilan sampel feses dan diperiksa menggunakan metode formol ether concentration di Laboratorium Parasitologi Fakultas Kedokteran Universitas Sebelas Maret. Data sanitasi lingkungan rumah diperoleh dengan questioner dengan metode observasi. Hasil penelitian menunjukkan bahwa prevalensi kejadian infeksi kecacingan pada anak sekolah dasar di SD Barengan adalah 40,21\%. Jenis lantai, ketersediaan air bersih, kepemilikan tempat sampah, dan sarana pembuangan air limbah berhubungan dengan kejadian infeksi kecacingan. Kepemilikan jamban tidak berhubungan dengan kejadian infeksi kecacingan pada anak sekolah dasar. Sanitasi lingkungan rumah berhubungan dengan kejadian infeksi kecacingan pada anak sekolah dasar.
\end{abstract}

Kata kunci: Anak sekolah dasar, infeksi kecacingan, sanitasi lingkungan rumah

\begin{abstract}
Nutrition is one of the human resources quality determinants. Nutritional problems are not only influenced by the lack of food intake but also influenced by infections.One of them is worm infection. The worm life cycle is influenced by several factors, namely environmental sanitation, personal hygiene behavior, and socioeconomic demographic condition of the surrounding area. The purpose of the research was to evaluate the relation of house sanitation to the incidence of infection of worm infection in primary school children. The research used was the observational technique with the
\end{abstract}


cross-sectional design, in the population of primary school children grade 1 to grade 5 in Barengan PrimarySchool, Teras subdistrict, Boyolali District. The data of child worm infection were obtained by stool sampling and examined using the method of formol-ether concentration at the Parasitology Laboratory of the Faculty of Medicine, Universitas SebelasMaret. Environmental sanitation data of the house was obtained by questioner with observation method. The result indicated that the prevalence of the worm infection in children of Barengan Primary School was $40.21 \%$. The type of floor, the availability of clean water, the ownership of the dumpster, and the waste disposal facilities were related to the incidence of infection of the infection. The latrine ownership was not related to the incidence of infection of worms in primary school children. Sanitation of the home environment was related to the incidence of infection worm in primary school children.

Keywords: Primary school children, infection of worms, sanitation of home environment

\section{PENDAHULUAN}

Gizi merupakan salah satu faktor penentu kualitas sumber daya manusia. Gizi kurang disebabkan oleh faktor langsung dan tidak langsung. Faktor penyebab tidak langsung meliputi tidak tersedianya pangan dalam rumah tangga, pola asuh anak yang tidak memadai, sanitasi air bersih, pelayanan kesehatan dasar yang tidak memadai, rendahnya tingkat pendidikan, pengetahuan dan keterampilan orang tua. Sedangkan faktor penyebab langsung meliputi asupan makanan yang tidak seimbang dan penyakit infeksi (UNICEF, 1998).

Penyakit infeksi yang dapat menyebabkan gizi kurang, salah satunya adalah infeksi kecacingan (Waryana, 2010). Anak sekolah dasar merupakan golongan yang paling beresiko terhadap kejadian infeksi kecacingan khususnya dinegara berkembang (Augusto et al., 2009; Shang et al., 2010). Di Amerika Latin dan Karibia diperkirakan $\pm 13,9$ juta anak usia prasekolah dan 35,4 juta anak usia sekolah berada pada risiko infeksi kecacingan (Saboya et al., 2013). Prevalensi kecacingan di Indonesia pada tahun 2012 masih tinggi yaitu 22,6\% dengan prevalensi tertinggi di Kabupaten Gunung Mas Kalimantan Tengah $(76,67)$ dan Kabupaten Lebak (62\%) (Kemenkes, 2012).

Tingginya prevalensi kecacingan disebabkan banyak faktor yang mempengaruhi siklus hidup cacing ini yaitu kondisi sanitasi lingkungan yang tidak memadai, perilaku personal hygiene yang kurang, serta kondisi sosio ekonomi demografi daerah sekitar (Dachi, 2005; WHO, 2013).

Infeksi cacing tanah ditularkan karena dipengaruhi oleh faktor lingkungan (Chammartin et al., 2013), sanitasi lingkungan yang buruk, (Andaruni et al., 2012; Debalke et al., 2013; WHO, 2013) meliputi sanitasi sumber air, pembuangan kotoran manusia, sanitasi makanan (Andaruni et al., 2012; Kundaian et al., 2011).

Tanah yang gembur serta suhu yang optimal, maka telur akan tumbuh dan berkembang menjadi telur infektif (Soedarto, 2011). Kondisi sosio demografi yang berbeda di setiap wilayah juga memicu tingginya prevalensi infeksi kecacingan yang berbeda-beda. Tempat yang lembab merupakan daerah endemik 
cacing. SD Barengan merupakan sekolah dasar yang terletak di Kecamatan Teras Kabupaten Boyolali, Provinsi Jawa Tengah. Kecamatan ini memiliki kondisi sosio demografi yang secara teori mendukung terjadinya infeksi kecacingan, karena merupakan daerah pertanian yang memiliki tanah liat dan gembur serta suhu yang optimum untuk perkembangbiakan cacing.

\section{METODE PENELITIAN}

Penelitian ini merupakan penelitian observasional dengan rancangan cross sectional, pada anak sekolah dasar di SD Barengan Kecamatan Teras Kabupaten Boyolali. Populasi dalam penelitian ini adalah anak kelas $1-5$ yang diambil secara acak. Pemeriksaan sampel feses untuk deteksi infeksi kecacingan dilakukan di Laboratorium Parasitologi FK-UNS dengan metode formol ether concentration. Data sanitasi lingkungan rumah didapatkan dari data kuesioner dengan indikator kondisi lantai, sarana air bersih, ketersediaan jamban (WC), sarana pembuangan air limbah dan sarana pembuangan sampah yang mengacu kepada lembar observasi sanitasi menurut Kemenkes. Data sanitasi lingkungan rumah diperoleh dengan cara pengamatan langsung ke rumah responden. Analisis data menggunakan chi square.

\section{HASIL DAN PEMBAHASAN}

\section{Karakteristik Subyek Penelitian}

Tabel 1. Distribusi Frekuensi Karakteristik Subyek Penelitian

\begin{tabular}{|c|c|c|}
\hline \multirow{2}{*}{ Karakteristik } & \multicolumn{2}{|c|}{ Total } \\
\hline & Frekuensi (n) & $(\%)$ \\
\hline \multicolumn{3}{|l|}{ Kelas } \\
\hline a. I & 17 & 22,97 \\
\hline b. II & 12 & 16,22 \\
\hline c. III & 19 & 25,68 \\
\hline d. IV & 14 & 18,92 \\
\hline e. & 12 & 16,22 \\
\hline Jumlah & 74 & 100,00 \\
\hline \multicolumn{3}{|l|}{ Jenis Kelamin } \\
\hline a. Laki-laki & 38 & 51,35 \\
\hline b. Perempuan & 36 & 48,65 \\
\hline Jumlah & 74 & 100,00 \\
\hline \multicolumn{3}{|l|}{ Usia } \\
\hline c. $7-9$ tahun & 37 & 50,00 \\
\hline d. 10-12 tahun & 37 & 50,00 \\
\hline Jumlah & 74 & 100,00 \\
\hline
\end{tabular}

Pada Tabel 1 diketahui jumlah subyek penelitian adalah 74 anak sekolah dasar. Berdasarkan penelitian ini ditemukan bahwa persentase infeksi kecacingan pada anak sekolah dasar di SD Barengan Kecamatan Teras Kabupaten Boyolali adalah 40,21\%, hal ini masih berada diatas target nasional yang ingin dicapai Indonesia yaitu $<20 \%$ (Kemenkes 2012).

\section{Distribusi Frekuensi Berdasarkan Pemeriksaan Laboratorium}

Hasil pemeriksaan menunjukkan bahwa dari 92 siswa yang dilakukan pemeriksaan feses, diperoleh 37 anak yang positif terinfeksi kecacingan.

Tabel 2. Distribusi Frekuensi Berdasarkan Pemeriksaan Laboratorium

\begin{tabular}{lcc}
\hline \multicolumn{1}{c}{ Variabel } & \multicolumn{2}{c}{ Total } \\
\cline { 2 - 3 } & $\begin{array}{c}\text { Frekuensi } \\
\text { (n) }\end{array}$ & $\%$ \\
\hline Jenis Infeksi & & \\
\hline a. Ascaris lumbricoides (A.l) & 20 & 54,05 \\
b. Trichuris trichiura & 1 & 2,70 \\
c. Hookworm & 10 & 27,03 \\
d. Oxyuris & 2 & 5,41 \\
e. A.l + Hookworm & 4 & 10,81 \\
\hline Jumlah & 37 \\
\hline Infeksi berdasarkan jenis kelamin & \multicolumn{1}{c}{} \\
\hline a. Laki-laki & 19 \\
b. Perempuan & 18 & 51,35 \\
\hline Jumlah & 37 \\
\hline
\end{tabular}

Jenis cacing yang paling banyak menginfeksi adalah cacing Ascaris lumbricoides sebanyak 20 siswa (54,05\%), infeksi Trichuris trichiura sebanyak 1 siswa (2,70\%), infeksi hookworm sebanyak 10 siswa $(27,03 \%)$, oxyuris sebanyak 2 siswa $(5,41 \%)$ serta yang terinfeksi Ascaris lumbricoides dan Hookworm sebanyak 4 siswa $(10,81 \%)$. Infeksi cacing yang paling banyak adalah jenis cacing Ascaris lumbricoides. Sejalan dengan penelitian Samudar (2013) yang paling banyak menginfeksi adalah cacing Ascaris lumbricoides, akan tetapi yang paling jarang menginfeksi adalah cacing tambang. Hal ini juga didukung oleh Fakhrina \& Wulandari (2007); Nur et al., 2013; Ekpo et al. (2008) cacing yang 
paling banyak menginfeksi adalah Ascaris lumbricoides.

Prevalensi infeksi kecacingan di Bolivia merupakan prevalensi tertinggi yang ada di Amerika Latin. Infeksi cacing Ascaris lumbricoides (38,0\%), Trichuris trichiura (19,3\%), dan hookworm $(11,4 \%)$ (Chammartin et al., 2013). Pada Tabel 2 diketahui julah subyek laki-laki lebih banyak terinfeksi kecacingan dibandingkan dengan perempuan, hal ini sejalan dengan penelitian Rayapu et al. (2012) menunjukkan bahwa dari 135 anak sekolah, laki - laki yang terinfeksi kecacingan $(25,75 \%)$ dan pada perempuan $(27,53 \%)$. Berbeda dengan penelitian Samudar (2013); Uga et al., (2005) menunjukkan, infeksi kecacingan pada perempuan lebih tinggi dibandingkan dengan laki-laki. Hasil penelitian dari Tekeste et al. (2013) menunjukkan bahwa tingkat infeksi kecacingan tinggi pada jenis kelamin perempuan sebanyak $25.64 \%$ sedangkan pada laki-laki yang terinfeksi kecacingan sebanyak $21.18 \%$.

Secara umum faktor-faktor yang mempengaruhi kecacingan, antara lain kondisi iklim yang sesuai untuk pertumbuhan cacing, kondisi sanitasi lingkungan dan hygiene perseorangan yang buruk serta keadaan sosial ekonomi dan pendidikan yang rendah (Dachi, 2005).

\section{Hubungan sanitasi lingkungan rumah terhadap kejadian infeksi kecacingan}

Tabel 3. Indikator sanitasi lingkungan rumah dengan kejadian infeksi kecacingan

\begin{tabular}{lc}
\hline \multicolumn{1}{c}{ Indikator } & p-value \\
\hline a. Lantai & 0.005 \\
b. Sarana air bersih & 0.005 \\
c. Kepemilikan jamban & 0.500 \\
d. Tempat sampah & 0.000 \\
e. Sarana pembuangan air limbah & 0.000 \\
\hline
\end{tabular}

Pada penelitian ini, sanitasi lingkungan rumah secara keseluruhan dilihat berdasarkan komponen rumah (langit-langit, dinding, lantai, jendela kamar tidur, jendela ruang keluarga, ventilasi, sarana pembuangan asap dapur, pencahayaan) dan sarana sanitasi (sarana air bersih, jamban, sarana pembuangan limbah dan sarana pembuangan tempat sampah).

Berdasarkan uji statistic pada Tabel 3 , terdapat hubungan antara kondisi lantai dengan kejadian infeksi kecacingan pada anak sekolah dasar di SD Barengan Kecamatan Teras Kabupaten Boyolali $\mathrm{p}=0.005(\mathrm{p}<0.05)$. Dari hasil pengamatan diketahui bahwa masih terdapat rumah dengan kondisi lantai dengan tanah dan ada yang diplester akan tetapi sudah retak -retak dan berdebu. Menurut Rahayu dan Ramdani, (2013) rumah dengan jenis lantai yang bukan terbuat dari tanah akan menurunkan risiko terjadi kecacingan dibandingkan rumah yang berjenis lantai dari tanah. Rumah yang memiliki lantai bukan tanah terproteksi lebih rendah terjadi kecacingan dibandingkan lantai yang terbuat dari tanah.

Air dapat sebagai faktor utama dalam berbagai penularan penyakit seperti thypus, dysentery, diare, kholera dan kecacingan (Sutrisno, 2004). Terdapat hubungan antara ketersediaan air bersih dengan kejadian infeksi kecacingan pada anak sekolah dasar di SD Barengan Kecamatan Teras Kabupaten Boyolali $\mathrm{p}=0.005(\mathrm{p}<0.05)$. Hal ini sejalan dengan beberapa penelitian sebelumnya yang menunjukkan adanya hubungan antara tersedianya akses air bersih dengan kejadian infeksi kecacingan. Ketersediaan air bersih yang kurang, dapat meningkatkan penularan resiko infeksi kecacingan (Alemu et al., 2011; Ngui et al., 2011; Kounnavong et al., 2011).

Kepemilikan jamban merupakan faktor risiko infestasi kecacingan (Sali et al., 2013). Tidak terdapat hubungan antara ketersediaan jamban dengan kejadian infeksi kecacingan pada anak sekolah dasar di SD Barengan Kecamatan Teras 
Kabupaten Boyolali $\mathrm{p}=0.500 \quad(\mathrm{p}>0.05)$ (Tabel 3). Berbeda dengan penelitian (Ngui et al., 2011; Ilechukwu et al., 2010; Tanner et al., 2011) yang menyebutkan bahwa ketersediaan jamban merupakan factor resiko kejadian infeksi kecacingan. Perbedaan ini dikarenakan semua rumah sudah memiliki jamban.

Terdapat hubungan antara kepemilikan tempat sampah dengan kejadian infeksi kecacingan pada anak sekolah dasar di SD Barengan Kecamatan Teras Kabupaten Boyolali $\mathrm{p}=0.000$ $(\mathrm{p}<0.05)$ (Tabel 3). Hal ini sejalan dengan penelitian Ngui et al. (2011) bahwa ketersediaan tempat sampah memiliki hubungan terhadap terjadinya infeksi kecacingan. Menurut Fitri et al, (2012) rumah dengan tempat sampah yang tidak memenuhi syarat kesehatan berpeluang 4,092 kali terinfeksi kecacingan dibandingkan rumah dengan tempat sampah yang memenuhi syarat kesehatan.

Ketersediaan sarana pembuangan air limbah (SPAL) berhubungan dengan kejadian infeksi kecacingan pada anak sekolah dasar di SD Barengan Kecamatan Teras Kabupaten Boyolali p $=0.000$ $(\mathrm{p}<0.05)$ (Tabel 3). Penelitian ini sejalan dengan penelitian Nur et al.(2013). Sarana pembungan air limbah rumah tangga sebaiknya di buang ke dalam tanah dengan membuat resapan di halaman atau tempat lain di sekitar rumah, yang syaratnya paling sedikit berjarak 10 meter dari sumur (Machfoedz, 2008). Pengelolaan air limbah bertujuan agar tidak mencemari air, tanah dan lingkungan. Air limbah banyak mengandung bibit penyakit, sehingga pengolahan air limbah perlu dilakukan untuk mencegah terjadinya pencemaran air limbah dilingkungan. Pencemaran limbah di lingkungan menyebabkan berbagai macam penyakit, salah satunya adalah penyakit kecacingan (Notoatmojo, 2007).

Tabel 4. Hubungan sanitasi lingkungan rumah terhadap kejadian infeksi kecacingan

\begin{tabular}{|c|c|c|c|c|c|c|}
\hline \multirow{3}{*}{$\begin{array}{c}\text { Infeksi } \\
\text { Kecacingan }\end{array}$} & \multicolumn{4}{|c|}{ Sanitasi Rumah } & \multirow{3}{*}{ OR } & \multirow{3}{*}{ Sig. $p$} \\
\hline & \multicolumn{2}{|c|}{ Kurang } & \multicolumn{2}{|c|}{ Baik } & & \\
\hline & $\mathbf{n}$ & $\%$ & $\mathbf{n}$ & $\%$ & & \\
\hline Positif & 35 & 94,6 & 2 & 5,4 & & \\
\hline Negatif & 12 & 32,4 & 25 & 67,7 & 36,458 & 0,000 \\
\hline Total & 47 & 63,5 & 27 & 36,5 & & \\
\hline
\end{tabular}
observasi keseluruhan indikator pada sanitasi lingkungan rumah dari hasil analisis statistik menunjukkan nilai signifikan $\mathrm{p}=0.000 \quad(\mathrm{p}<0.05)$, hal ini menunjukkan bahwa terdapat hubungan sanitasi lingkungan rumah terhadap kejadian infeksi kecacingan pada anak sekolah dasar. Anak dengan sanitasi lingkungan rumah yang kurang memiliki kecenderungan untuk terinfeksi cacing sebesar 36,458 atau 36 kali lebih besar dibandingkan dengan anak yang sanitasi lingkungan rumahnya baik.

\section{KESIMPULAN}

Terdapat hubungan antara sanitasi lingkungan rumah terhadap kejadian infeksi kecacingan pada anak sekolah dasar.

\section{DAFTAR PUSTAKA}

Alemu, A., Atnafu, A., Addis, Z., Shiferaw, Y., Teklu, T., Mathewos, B., Birhan, W., Gebretsadik, S., dan Gelaw, B., 2011, Soil Transmitted Helminths and Schistosoma mansoni Infections among School Children in Zarima Town, Northwest Ethiopia, BMC Infectious Diseases, vol. 11, no. 189. 
Andaruni, A., Sari, F., dan Bangun, S., 2012, Gambaran Faktor-Faktor Penyebab Infeksi Cacingan pada Anak Di SDN 01 Pasirlangu Cisarua, Fakultas Ilmu Keperawatan Universitas Padjajaran Bandung.

Augusto, G., Nala, R., Casmo, V., Sabonete, A., Mapaco, L., dan Monteiro, J., 2009, Geographic Distribution and Prevalence of Schistosomiasis and SoilTransmitted Helminths among School Children in Mozambique, American Journal of Tropical Medicine and Hygiene, vol. 81, no.5, hlm. 799803.

Chammartin, F, Scholte, R.G.C., Malone, J.B., Bavia, M.E., Nieto, P., Utzinger, J., dan Vounatsou, P., 2013, Modelling The Geographical Distribution of SoilTransmitted Helminth Infections in Bolivia, Parasiet Vectors 6; 152.

Dachi, R. A., 2005, Hubungan Perilaku Anak Sekolah Dasar No.174593 Hatoguan Terhadap Infeksi Cacing Perut di Kecamatan Palipi Kabupten Samosir, http://repository.usu.ac.id, diakses tanggal 23 Maret 2016.

Debalke, S., Worku, A., Jahur, N., dan Mekonnen, Z., 2013, Soil Transmitted Helminths and Associated Factors among School Children in Government and Private Primary School in Jimma Town, Southwest Ethiopia, Ethiopian Journal of Health Science, vol. 23, no. 3.

Ekpo, U.F., Odoemene, S., Mafiana, C.F. dan Wobo., 2008, Helminthiasis and Hygiene Conditions of Schools in Ikenne, Ogun State, Nigeria, PLoS Neglected Tropical Diseases, vol. 2, Issue 1 e146.

Fakhrina, A dan Wulandari K., 2007, Infestasi Nematoda Usus pada Balita di Desa Timbulharjo, Kecamatan Sewon, Kabupatan Bantul, Yogyakarta, Hubungannya dengan Faktor-Faktor Resiko Pasca GempaI. Fakultas Kedokteran Universitas Muhammadiyah Yogyakarta. Yogyakarta. Available at http://publikasi.umy.ac.id/index.php/pend-dokter/article/view/4754/4061, diakses tanggal 12 April 2016.

Fitri, J., Saam, F.J., dan Hamidy, Z., 2012, Analisis Faktor-Faktor Risiko Infeksi Kecacingan Murid Sekolah Dasar Di Kecamatan Angkola Timur Kabupaten Tapanuli Selatan Tahun 2012, Jurnal Lingkungan, ISSN 1978-5283.

Ilechukwu, G.C., Ilechukwi, C.G.A., Ozumba, A.N., Ojinnaka, N.C., Ibe, B.C., dan Onwasigwe., C.N., 2010, Some Behavioural Risk Factors for Intestinal Helminthiasis in Nursery and Primary School Children Inenugu South Easthern Nigeria, Nigerian Journal of Clinical Practice, vol. 13, no.3, hlm 288-293.

Kemenkes RI., 2012, Pengendalian Penyakit dan Penyehatan Lingkungan Tahun 2012. Kementerian Kesehatan Republik Indonesia.

Kounnavong, S., Vonglokham, M., Houamboun, K., Odermatt, P., dan Boupha, B., 2011, Soil-Transmitted Helminth Infections and Risk Factors in Preschool 
Children in Southern Rural Lao People's Democratic Republic, Transactions of the Royal Sociaty of Tropical Medicine and Hygiene, vol. 105, hlm. 160-166.

Kundaian, F., Umboh, J.M.L., dan Kepel., 2011, Hubungan Antara Sanitasi Lingkungan dengan Infestasi Cacing pada Murid Sekolah Dasar di Desa Teling Kecamatan Tombariri Kabupaten Minahasa. Fakultas Kesehatan Masyarakat Universitas Sam Ratulangi Manado.

Machfoedz, I., 2008, Menjaga Kesehatan Rumah dari Berbagai Penyakit, Fitramaya, Yogyakarta.

Ngui, R., Ishak, S., Chuen, C.S., Mahmud, R., dan Lim, Y.A.L., 2011, Prevalensi and Risk Factors of Intestinal Parasitism in Rural and Remote West Malaysia, PLoS Neglacted Tropical Disease, vol. 5, no. 3, e974.

Notoatmodjo, S., 2007, Promosi Kesehatan dan Ilmu Perilaku, Rineka Cipta, Jakarta.

Nur, M.I., Ane, R.L., dan Selomo, M., 2013, Faktor Risiko Sanitasi Lingkungan Rumah Terhadap Kejadian Kecacingan Pada Murid Sekolah Dasar Di Pulau Barrang Lompo Kota Makassar Tahun 2013. Makassar: Bagian Kesehatan Lingkungan, Fakultas Kesehatan Masyarakat, UNHAS.

Rahayu dan Ramdani., 2013, Faktor Resiko Terjadinya Kecacingan di SDN Tebing Tinggi di Kabupaten Balangan Provinsi Kalimantan Selatan, Jurnal Epidemiologi dan Penyakit Bersumber Binatang.

Rayapu, V., Dhandapany, SP., Shaker, I. dan Kasukurthy, S., 2012, Prevalence of Intestinal Helminthic Parasites in School Going Children in Rural Area of Kuppam, Andhra Pradesh, International Journal of Basic Medical Sciences and Pharmacy (IJBMSP) Vol. 2, No. 2, hlm. 2049-4963.

Saboya, M.I., Catala, L., Nicholls, R.S., dan Ault, S.K., 2013, Update on the Mapping of Prevalence and Intensity of Infection for Soil-Transmitted Helminth Infections in Latin America and the Caribbean: A Call for Action, PLOS Neglected Tropical Diseases, vol. 7, Issue. 9, e2419.

Sali, L., Abdullah, Z., dan Suriah., 2013, Faktor Risiko Infestasi Soil Transmitted Helmiths Pada Anak Usia Sekolah, Fakultas Kesehatan Masyarakat: Universitas Hasanuddin.

Samudar., 2013, Hubungan Infeksi Kecacingan Dengan Status Hemoglobin Pada Anak Sekolah Dasar Diwilayah Pesisir Kota Makassar Propinsi Sulawesi Selatan Tahun 2013, Prodi Ilmu Gizi, Makasar.

Shang Y, Tang LH, Zhou SS, Chen YD, Yang YC, Lin SX., 2010, Stunting and soiltransmitted-helminth infections among school-age pupils in rural areas of southern China, Parasit Vectors. 2010 Oct 13; 3: 97. doi: 10.1186/1756-33053-97. 
Soedarto., 2011. Buku Ajar Parasitologi Kedokteran, Sagung Seto, Jakarta.

Sutrisno, T., 2004, Teknologi Penyediaan Air Bersih, PT Rineka Cipta, Jakarta.

Tanner, S., Choque, M.E.C., Huanca, T., Thomas, W., William, R.L., dan Victoria, R.G., 2011, The Effects of Local Medicinal Knowledge and Hygiene on Helminth Infections in an Amazonian Society, Social Science \& Medicine, vol. $72,701 \mathrm{e} 709$.

Tekeste, Z., Belyhun, Y., Gebrehiwot, A., Moges, B., Workineh, M., Ayalew, G., Mandefro, M., dan Kassu, A., 2013, Epidemiology of Intestinal Schistosomiasis and Soil Transmitted Helminthiasis among Primary School Children in Gorgora, Northwest Ethiopia, Asian Pacific Journal of Tropical Medicine, vol. 3, no. 1, hlm. 61-64.

Uga, S., Hoa, Ng.T.V., Thuan, L.K., Noda, S., dan Fujimaki, Y., 2005. Intestinal Parasitic Infections in Schoolchildren in A Suburban Area of Hanoi, Vietnam, Southeast Asian Journal of Tropical Medicine and Public Health, Bangkok, vol. 36, hlm. 1407-1411UNICEF. 1998. The State of The World's Children. Oxford University Press, New York.

UNICEF., 1998, The State of The World's Children, Oxford University Press, New York.

Waryana., 2010, Gizi Reproduksi, Pustaka Rihama, Yogyakarta.

WHO. 2013. Soil-Transmitted Helminth Infections (online). Available from: http://www.who.int/mediacentre/factsheets/fs366/en/, diakses tanggal 25 April 2016. 